\title{
Multi-CRITERIA ANALYSIS OF TECHNICAL SOLUTIONS FOR ROAD INTERSECTION RECONSTRUCTION: AN APPLICATION OF AHP METHOD
}

\author{
BARIC, D.
}

Abstract: Building or reconstructing a road intersection to make it safe and efficient requires considering several factors including traffic characteristics, geometric elements, local constraints, etc. On the other hand, every investment needs to be analysed from the financial point of view. While considering different selection criteria, multi-criteria analysis is necessary to select the optimal technical solution. The main objective of this study is to apply the AHP (Analytic Hierarchy Process) method to evaluate the possible variants for the reconstruction of road intersection through various criteria and sub-criteria. The AHP method is one of the most applied multi-criteria methods for transport infrastructure evaluation. The research methodology and practical implementation of the AHP method are shown in the case study. Four developed variants are presented and evaluated by the AHP method using the Expert Choice software. The results confirmed the justification of applying the AHP method in the complex decision-making process for the optimal technical solution for road intersection reconstruction.

Key words: Multicriteria analysis, AHP, Analytic Hierarchy Process, road intersection, case study.
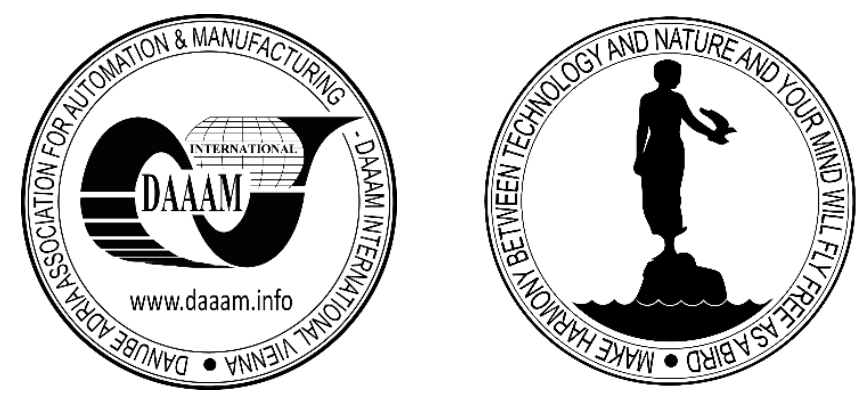

Authors' data: Assoc. Prof. Baric, D[anijela], University of Zagreb, Faculty of Transport and Traffic Sciences, HR-10000, Zagreb, Croatia, dbaric@ fpz.unizg.hr

This Publication has to be referred as: Baric, D[anijela] (2021). Multi-criteria Analysis of Technical Solutions for Road Intersection Reconstruction: An Application of AHP Method, Chapter 06 in DAAAM International Scientific Book 2021, pp.069084, B. Katalinic (Ed.), Published by DAAAM International, ISBN 978-3-902734-310, ISSN 1726-9687, Vienna, Austria

DOI: $10.2507 /$ daaam.scibook.2021.06 
Baric, D.: Multi-criteria Analysis of Technical Solutions for Road Intersection Reco...

\section{Introduction}

Road intersection is an essential part of the road network, and it plays a crucial role in many intelligent transportation applications (Tang et al., 2019). The role of road intersections is to merge and separate traffic flows. Based on this, there is mutual interaction between traffic participants in the intersection area, which results in the emergence of conflict and dangerous situations. With the occurrence of many traffic accidents and the observation of certain shortcomings of the design elements of the intersection that lead to possible dangers in traffic, the intersection needs to be reconstructed. For this purpose, possible traffic solutions are proposed in order to choose the optimal one.

Numerous methods are applied in the evaluation of transport solutions in the process of their evaluation and investment decision-making (Henke et al., 2020; Dzemydiene, 2021). The evaluation of each project is usually a multidimensional problem. On the one hand, financial analysis is very important, on the other, technical, social, and ecological factors are taken into account too (Nowak, 2005). The methods applied most often differ in optimization criteria. In the project evaluation phase, single-criterion and multi-criteria methods are used in decision-making. The method of cost-benefit analysis is highly represented in the project evaluation phase, but other multi-criteria decision-making methods are increasingly used for project evaluation. For the purpose of long-term and quality solutions, it is necessary to introduce several optimization criteria, i.e. the application of some of the methods of multi-criteria decision-making. Optimization criteria are based on economic, technological, technical, and environmental criteria, but also on some others, as well. Applying these methods is necessary for complex investment projects of great social significance, especially in transport infrastructure projects (Baric et al., 2007). Of the many multicriteria decision-making methods, the Analytic Hierarchy Process (AHP) method is one that is used most. The method is increasingly important in solving problems and making decisions in the field of transport (Saaty, 1995; Podvezko, 2009; Stojcic et al., 2019). The AHP method has proven valuable not just in traffic sciences but also in most other spheres of human activities, including civil engineering (Aghdaie et al., 2012; Ceric et al., 2013; Karleusa et al., 2013), marketing (Gholami \& SeyyedEsfahani, 2012), entertainment (Vidal et al., 2011) and the selection of academic staff (Rouyendegh \& Erkan, 2012). The AHP method can solve complex problems in transport infrastructure, including road intersections (Baric \& Pizeta, 2018; Surdonja et al., 2019), supporting decisions in the transport sector in the frame of drafting the Sustainable Energy and Climate Action Plan (D'orso et al., 2020), etc. In some studies, the AHP method is combine with other multi-criteria decision-making methods such as TOPSIS (Abd et al., 2017), ELECTRE (Zak \& Kruszyriski, 2015), VIKOR (Bakioklu et al., 2021), etc.

In this paper, the AHP method has been applied. The main goal of this study is to use the AHP method to evaluate the possible variants for the reconstruction of road intersection through various criteria and sub-criteria. The AHP model was applied to assess possible variants for reconstructing the intersection of Stubicka Street, Marija Juric Zagorka Street and Zagorsko naselje Street in Oroslavje. 
Traffic accidents were frequent at this intersection due to poor visibility, high access speeds and other factors. Based on the analysis of the existing situation, new variants of intersections were proposed, which were evaluated by multi-criteria analysis using the AHP method with the software support of Expert Choice. The aim of the research is to determine the optimal solution for the reconstruction of the intersection to contribute to increased safety, reduce traffic accidents, increase vehicle flow, and reduce environmental pollution, which ultimately leads to improved service levels of the intersection in the road network.

\section{Methodology of the AHP method}

The AHP method is a multi-objective, multi-criteria decision-making approach that employs a pairwise comparison procedure to arrive at a scale of preferences among sets of alternatives. To apply this technique, it is necessary to break down a complex unstructured problem into its parts; arraying these parts, or variables, into a hierarchic order; assigning numerical values to subjective judgments on the relative importance of each variable and synthesizing the judgments to determine which variables have the highest priority and should be acted upon to influence the outcome of the situation (Saaty, 1984).

To make a decision in an organised way to generate priorities, it is necessary to decompose the decision into the following steps.

- Define the problem and determine the kind of knowledge sought.

- Structure the decision hierarchy from the top with the goal of making the decision, then the objectives from a broad perspective, through intermediate levels (criteria on which subsequent elements depend) to the lowest level (which is usually a set of alternatives).

- Construct a set of pairwise comparison matrices. Each element in an upper level is used to compare the elements in the level immediately below with respect to it.

- Use the priorities obtained from the comparisons to weigh the priorities in the level immediately below for every element, continuing this process of weighing and adding until the final priorities of the alternatives in the bottom-most level are obtained.

For the pairwise comparison judgments, a scale of 1 to 9 is used. The numbers indicate the strength of preference for one over the other. Saaty names the scale as a Saaty scale, which features five main levels of intensity (1 - equal importance, 3 moderate importance, 5 - strong importance, 7 - very strong or demonstrated importance, 9 - extreme importance), as well as four intermediate levels ( 2 - weak or slight, 4 - moderate plus, 6 - strong plus, 8 - very, very strong), (Saaty, 1988). The best alternative is selected based on the defined total weight priority vector by synthesising all weight vectors, and the following expression describes it:

$$
W_{i}=\sum_{j=l}^{n} c_{j} w_{i j}, \quad \forall i=1, \ldots, m
$$


where $W_{i}$ represents weight, the priority of alternative $i ; c_{j}$ represents the weight of criterion $j(\mathrm{j}=1,2, \ldots, \mathrm{n}) ; w_{i j}$ represents alternative $i$ regarding criterion $j ; m$ represents the number of alternatives; and $n$ represents the number of criteria.

Saaty proved that for the consistent reciprocal matrix, the largest eigenvalue is equal to the number of comparisons, or $\lambda_{\max }=\mathrm{n}$. Then he defined the measure of consistency, called the Consistency Index (CI), which indicates the deviation or degree of consistency using the following formula

$$
C I=\frac{\lambda_{\max }-n}{n-1}
$$

Saaty proposed that the CI should be compared with the corresponding random CI (RI). Saaty randomly generated reciprocal matrices using scale and calculated the RI to determine whether it was approximately $10 \%$ or less. The Consistency Ratio (CR) compares the CI with RI:

$$
C R=\frac{C I}{R I}
$$

If CR is smaller or equal to $10 \%$, the inconsistency is acceptable. If CR is greater than $10 \%$, the preference needs to be revised (Saaty, 1984).

\section{Application of the AHP Method - Case Study}

Practical implementation of the AHP method is presented in a case study. A fourlane road intersection, not operated by traffic lights (Stubicka Street, Marija Juric Zagorka Street and Zagorsko naselje Street), located in Oroslavje, a small town (with up to 5,000 inhabitants), was chosen as an example in the case study.

\subsection{Problem, study area and data collection}

The problem of the intersection in question is multiple. It is a classic four-lane intersection that is not controlled by traffic signals, poorly lit, with poor visibility from side roads to the main direction, which reduces traffic safety. The intersection, with its technical elements, enables high speed of vehicles on the main driveways. Still, it has many points of conflict (a total of 32) and has therefore become a place of frequent traffic accidents.

When the impact of a four-lane classic intersection at a level that is not controlled by traffic lights is added to the number of conflict points, poor visibility and high speeds through the intersection, we get a "black spot" in the traffic network and maximum vulnerability of all the traffic participants. Data collection included the analysis of historical data on traffic accidents and the existing traffic flows at intersections.

Based on the data obtained from the Ministry of the Interior at this intersection in the last eight years, there were 20 traffic accidents in which 11 people were injured, which leads to the need for the reconstruction of this intersection (Ministry of the 
Interior, 2020). Fig. 1 shows the situation of the accident and the avoided traffic accident at the intersection in question. The circumstance of the traffic accident was non-compliance with giving the priority of passage, which included injured persons.

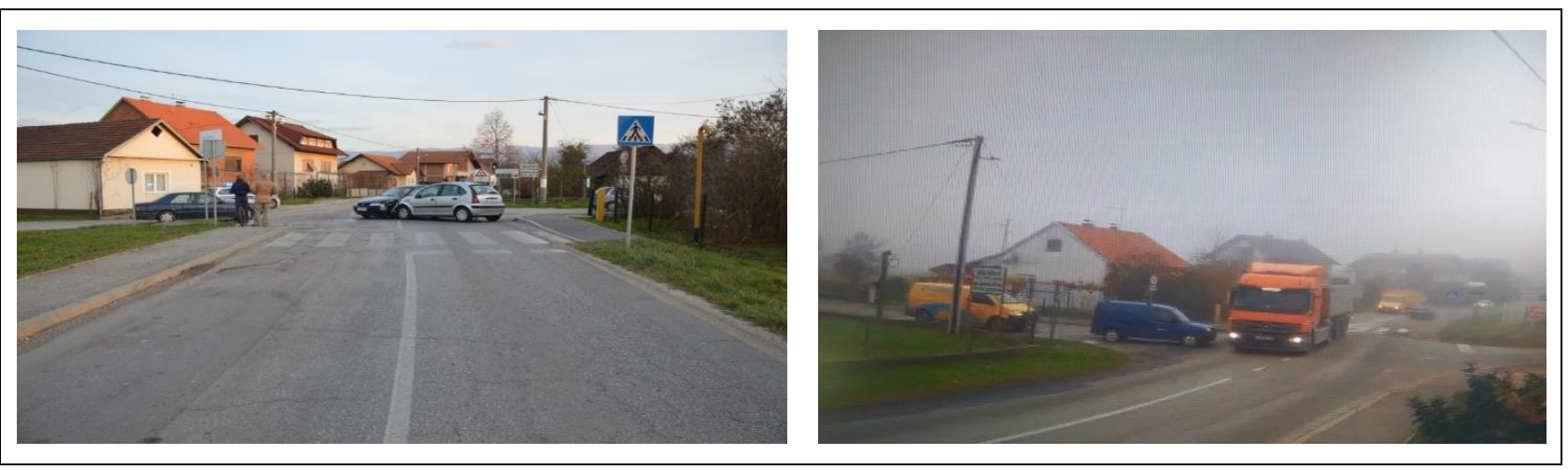

Fig. 1. Overview of the traffic accident and the avoided traffic accident at the intersection in question (Ministry of the Interior, 2019)

To obtain accurate data on the traffic load of the intersection, the traffic at the intersection was counted using special equipment for measuring traffic (equipment provided by the Faculty of Transport and Traffic Sciences). A COUNTcam camera was used to continuously record the intersection in question for 24 hours to obtain data on the traffic load of the intersection throughout the day (https://sestar.irb.hr/instrumenti_show.php?ID=3010\&page=0).

Then, the recorded data were processed in the software tool COUNTpro and COUNTpad 2 (https://sestar.irb.hr/instrumenti_show.php?ID=3011\&page=0). By registering the traffic, the daily traffic at the intersection in question was 8,469 vehicles, of which $96 \%$ were passenger cars and $4 \%$ trucks. There were 588 vehicles in the peak hour from 7 to 8 a.m. (Babic, 2019).

\subsection{Proposal of new alternatives for reconstruction}

Based on the analysis of the current situation and the identified shortcomings, four possible solutions for the reconstruction of the intersection in question were proposed, which would increase traffic safety of all traffic participants and reduce the time of arriving vehicles from secondary approaches of the intersection. The possible proposed solutions are:

- Alternative 1 - roundabout;

- Alternative 2 - intersection with a mini-roundabout;

- Alternative 3 - an intersection controlled by traffic lights;

- Alternative 4 - installation of new and renovation/replacement of the existing horizontal and vertical signalization and increasing the field of view from all entries.

The proposed alternatives result from research conducted at the Faculty of Transport and Traffic Sciences and in a master thesis (Babic, 2019). The proposed alternatives are shown in Fig. 2. 
Baric, D.: Multi-criteria Analysis of Technical Solutions for Road Intersection Reco...

Alternative 1 proposes the reconstruction of a four-lane level intersection into an intersection with a roundabout. At such an intersection, all vehicles from all driveways would have to slow down and give priority to the vehicles in the roundabout. At each driveway, there is one traffic lane for the entry and one for the exit from the intersection. Roundabouts provide the highest level of traffic safety. The speed of vehicles driving at an intersection with a roundabout is limited to $40 \mathrm{~km} / \mathrm{h}$, significantly reducing the possibility of a severe accident with serious consequences.

The roundabout has the dimensions of the outer diameter Dv $=13.5$ metres, the traffic lane is 7.5 metres wide, and the central island has a diameter of Ds $=6$ metres. All four driveways have entries with one traffic lane three metres wide. This variant requires high costs for constructing this type of roundabout because due to its size and construction, it is necessary to purchase the surrounding land and demolish the surrounding houses for its construction. Also, the disadvantage of such an intersection would be a slowdown in traffic on the main driveways.

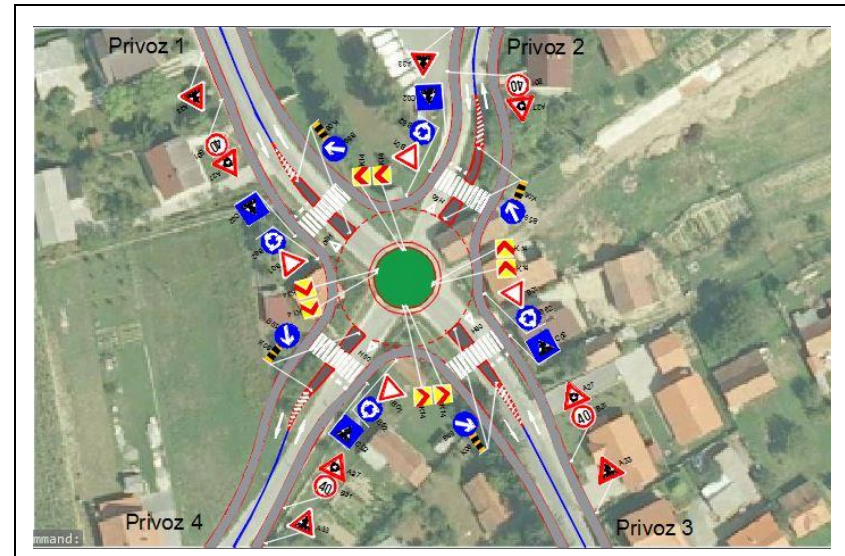

Alternative 1

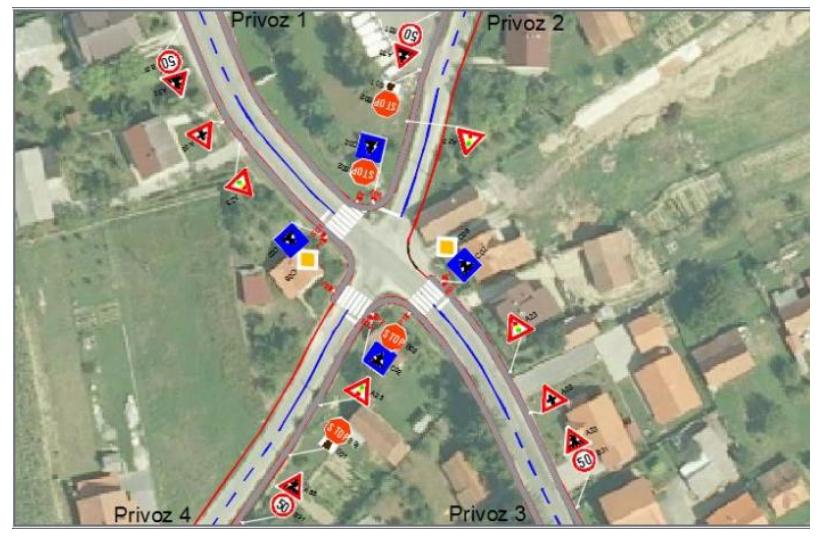

Alternative 3

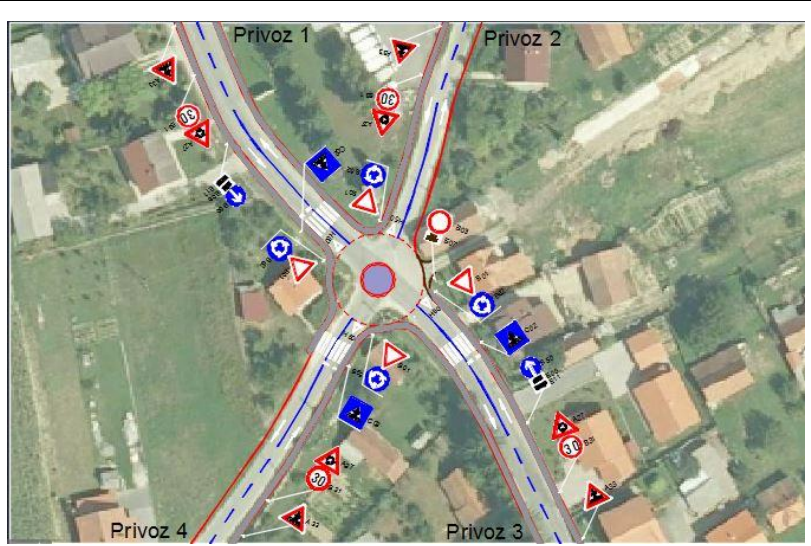

Alternative 2

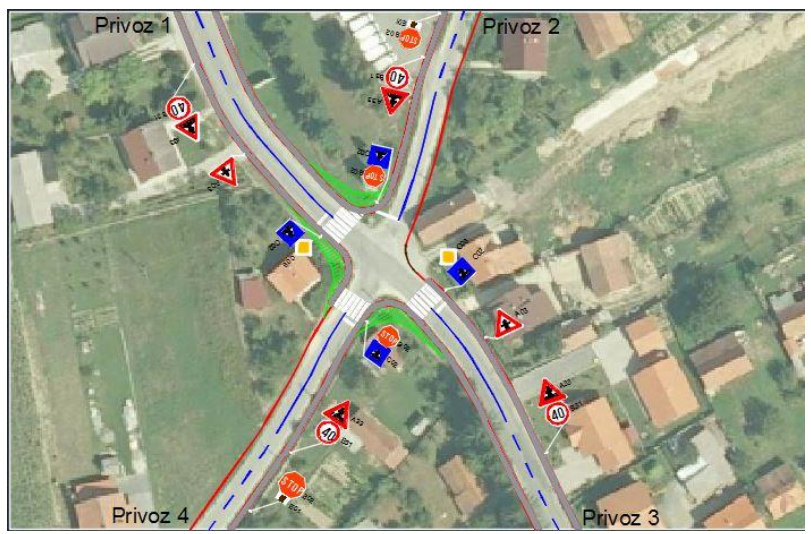

Alternative 4

Fig. 2. Proposal of possible alternatives for road intersection reconstruction (Babic, 2019)

Alternative 2 also implies reconstruction of a four-lane level intersection, but in this variant an intersection with a mini roundabout would be built. This alternative is structurally similar to Alternative 1 . It differs in the dimensions of certain technical elements of roundabouts. 
Each driveway consists of one traffic lane to enter and one to exit the intersection. The intersection has the shape of a mini one-lane roundabout with an outer diameter of $\mathrm{Dv}=9$ metres. The circular traffic lane is 6 metres wide, and the central transit island is Ds $=3$ metres in diameter. The speed of vehicles moving at an intersection with a mini-roundabout is limited to $30 \mathrm{~km} / \mathrm{h}$. The smaller dimensions of the roundabout and smaller radii for entering and/or exiting reduces the throughput and time of passage through the intersection.

The driving rules in mini-roundabouts are the same as for other types of roundabouts. Vehicles are expected to follow the circular trajectory around the central island and bypass it as otherwise, the probability of a collision increases. Longer vehicles, which due to the small radius, cannot bypass the central island, must pass over it in part or in full, and therefore the central part is raised only $2-3 \mathrm{~cm}$ from the pavement and it is passable for all vehicles. The costs for the construction of the miniroundabout are also high. However, they are still lower than Alternative 1 because only part of the surrounding land needs to be purchased for its construction, and there is no need to demolish nearby houses.

Alternative 3 proposes an intersection controlled by traffic lights. Intersections controlled by traffic lights belong to the group of specific intersections that do not differ in their design elements from the classic intersections, except that the traffic flow movement is regulated by traffic light signals. At the intersection controlled by traffic lights, the traffic flows are separated by time. Traffic lights can increase the level of safety and bandwidth of intersections. The use of intersections with the controlled traffic lights is recommended at intersections where the main traffic flow is often much more intense than the second traffic flow, which is the case at the intersection in question in the analysis of intersections discussed above. The intersections operated with traffic lights reduce the frequency and severity of the consequences of certain collisions, especially right-angle collisions (side collisions), and increase the intersection capacity. Each driveway consists of one traffic lane to enter and one to exit the intersection. This alternative has low costs because it does not require significant investments, which is reflected in the minimum of civil works compared to other variants.

The proposal in Alternative 4 is to install the missing signalization at the intersection and to renew or replace the existing one. The existing traffic signals on the sidewalks are made of Class II material (High Intensity Grade) and should be replaced with a newer generation of signalling materials of Class III (Diamond Grade) with greater retroreflection and a more extended guarantee of durability. Speed is limited to $40 \mathrm{~km} / \mathrm{h}$ due to the need for greater attention of drivers near the intersection due to reduced visibility on sidewalks and increased traffic safety of all participants. Each driveway consists of one traffic lane to enter and one to exit the intersection. This alternative has low costs because there is no need to purchase additional surrounding land, and no major construction works are required for its implementation (Babic, 2019). 


\subsection{AHP model}

According to Saaty (Saaty, 1984), the hierarchy structure of the AHP model consists of one objective, criteria, sub-criteria and alternatives. The evaluation of the proposed design solutions using the AHP method with the application of the software tool Expert Choice is performed. The AHP model considers seven criteria (safety, traffictechnology, costs, ecology, spatial-urban, complexity of the implementation of the intersection reconstruction, time required for reconstruction) and their 18 sub-criteria (Fig. 3). Four alternatives are presented before.

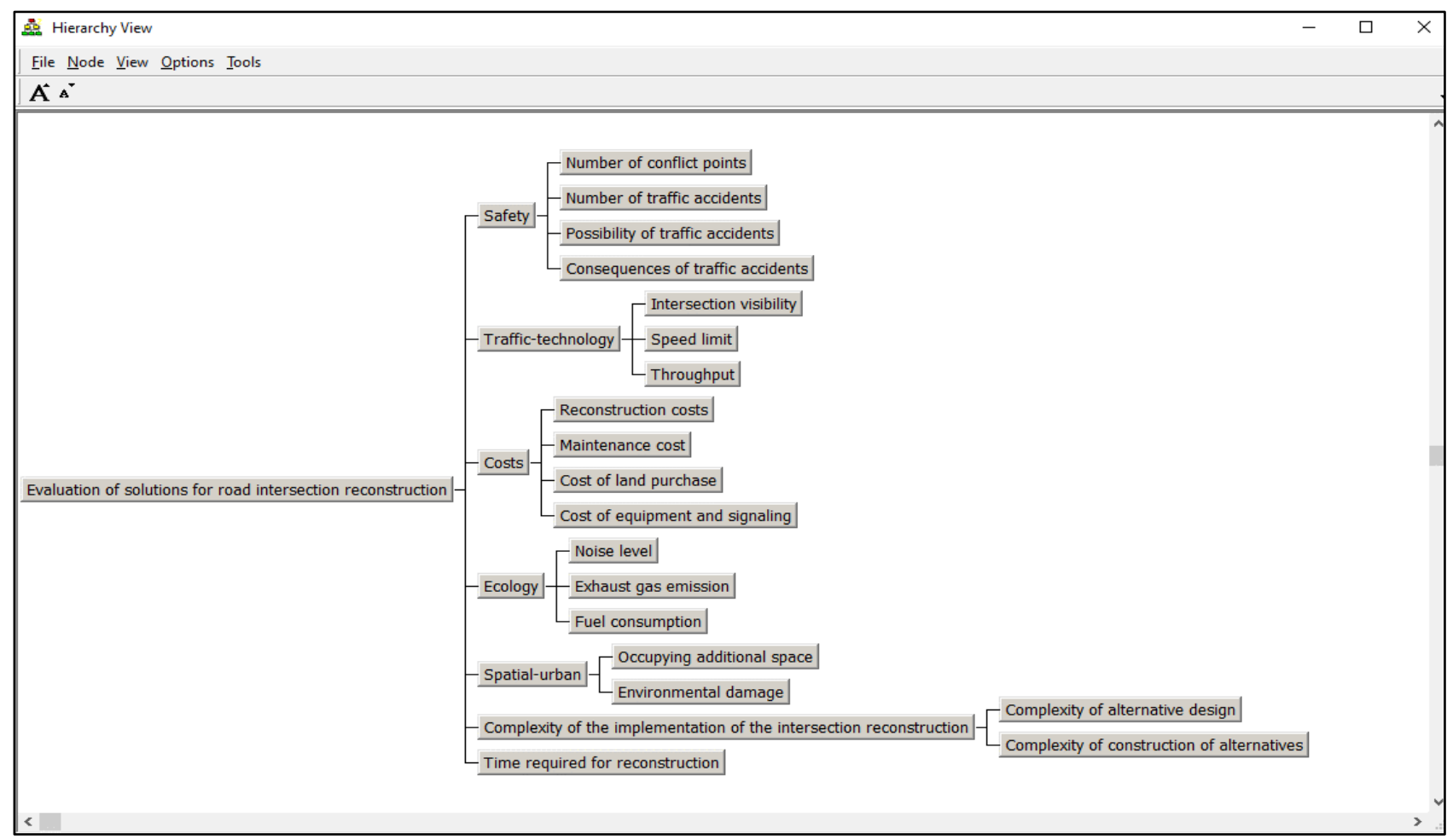

Fig. 3. Criteria and sub-criteria in the hierarchy structure of the AHP model

\subsection{Results}

After the problem has been structured, there comes the process of ranking the criteria and sub-criteria, followed by the evaluation of the variants according to each criterion and sub-criterion. The criterion safety (.389) has been allocated the highest importance. The second important is the criterion cost (.238), followed by traffic-technology (.172) due to all the advantages brought by the improvement of the traffic system, ecology (.097) due to the importance of adapting to the standards of environmental protection, spatial-urban (.050) due to the possibility of the implementation of the advanced solutions that occupy relatively little space, the complexity of the implementation of the intersection reconstruction (.031), time required for reconstruction (.023). The ranking of the criteria is shown in Fig. 4. 


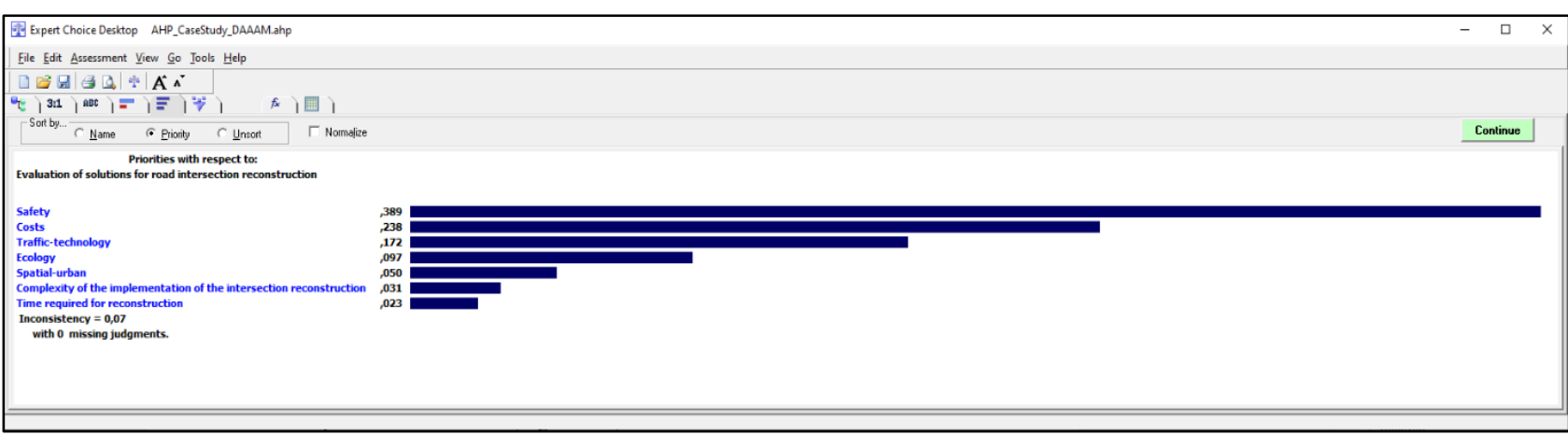

Fig. 4. Ranking of criteria

After having ranked the criteria, the sub-criteria were ranked as part of each criterion (Fig. $4-10)$.

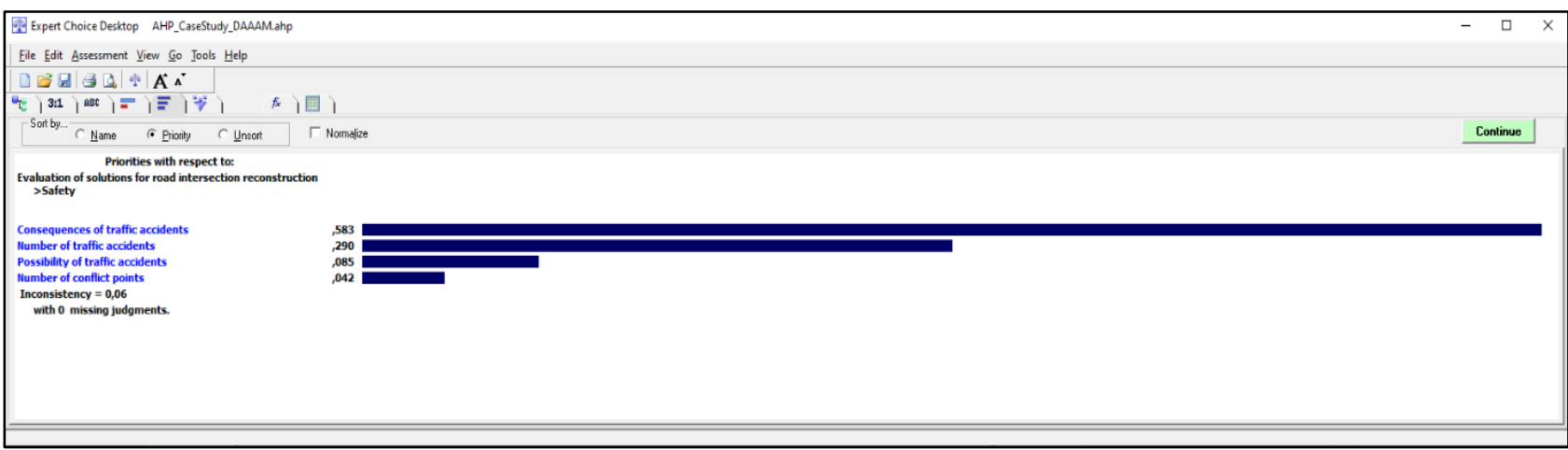

Fig. 5. Ranking of sub-criteria of the criterion "Safety"

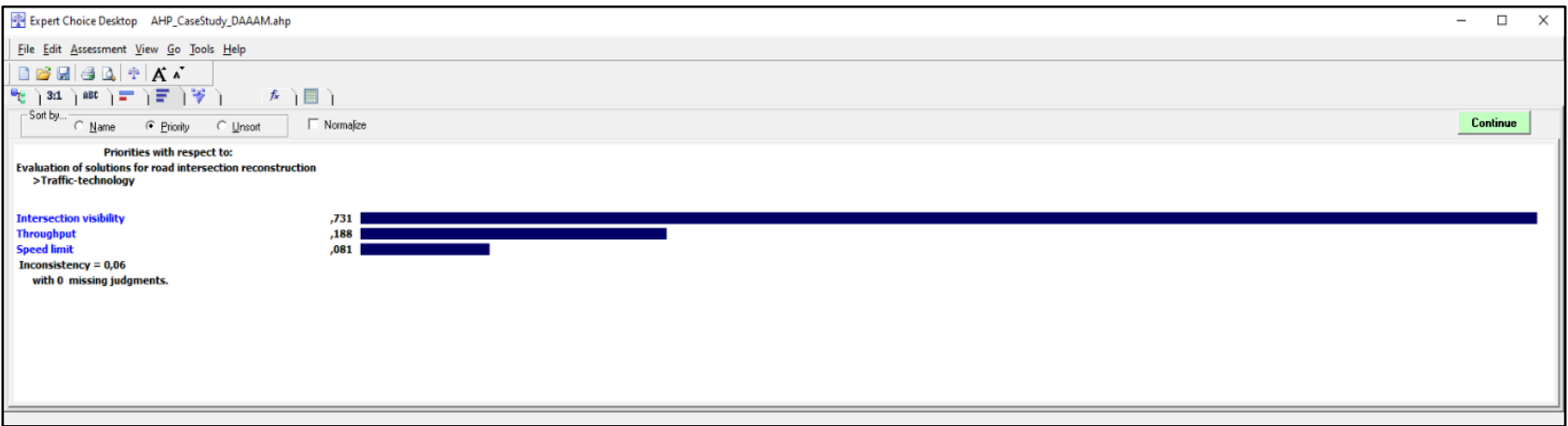

Fig. 6. Ranking of sub-criteria of the criterion "Traffic-technology"

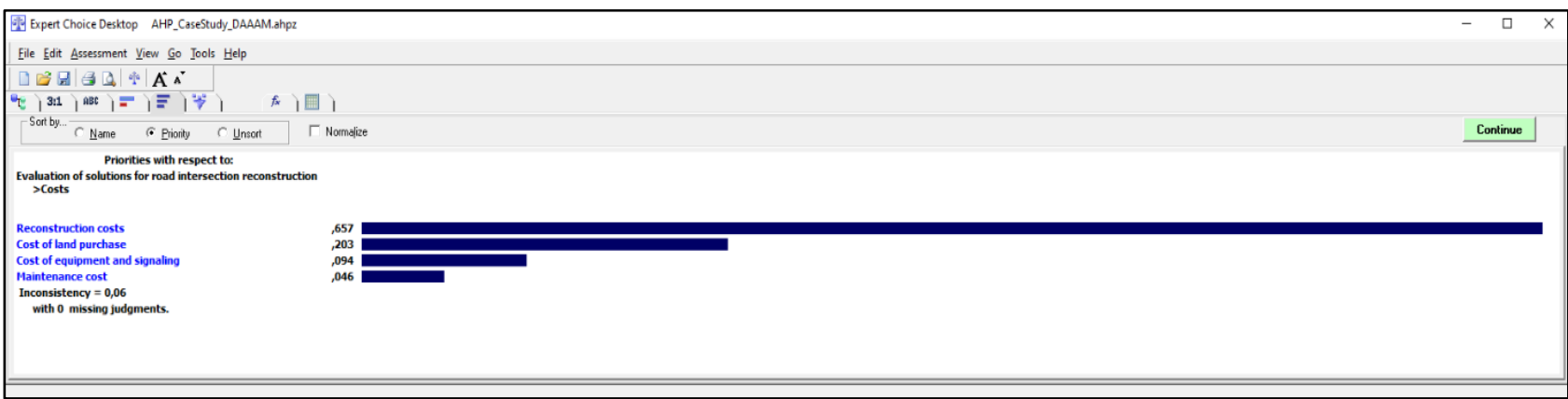

Fig. 7. Ranking of sub-criteria of the criterion "Costs" 
Baric, D.: Multi-criteria Analysis of Technical Solutions for Road Intersection Reco...

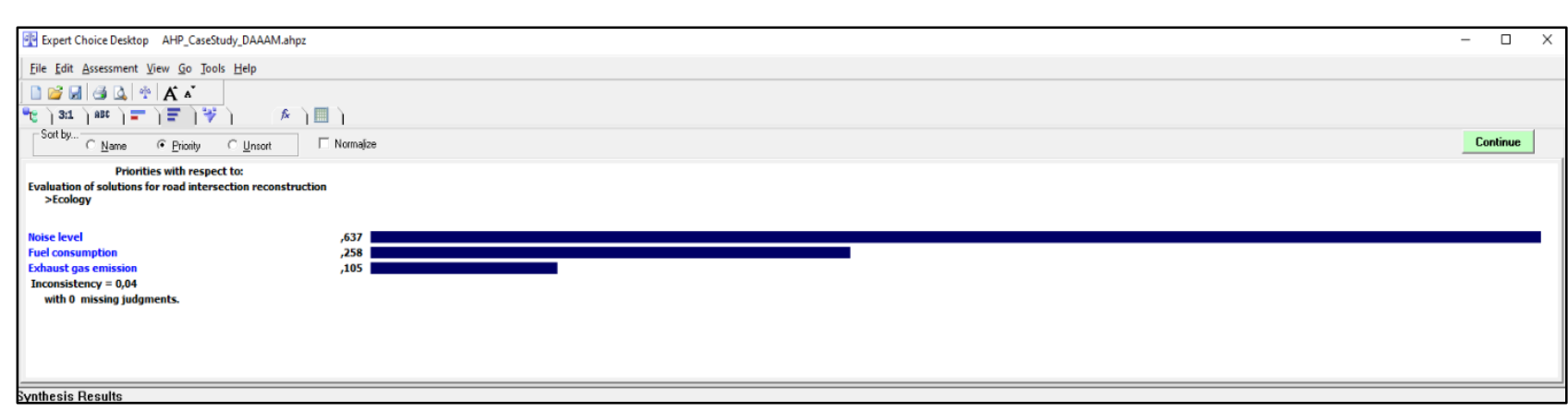

Fig. 8. Ranking of sub-criteria of the criterion "Ecology"

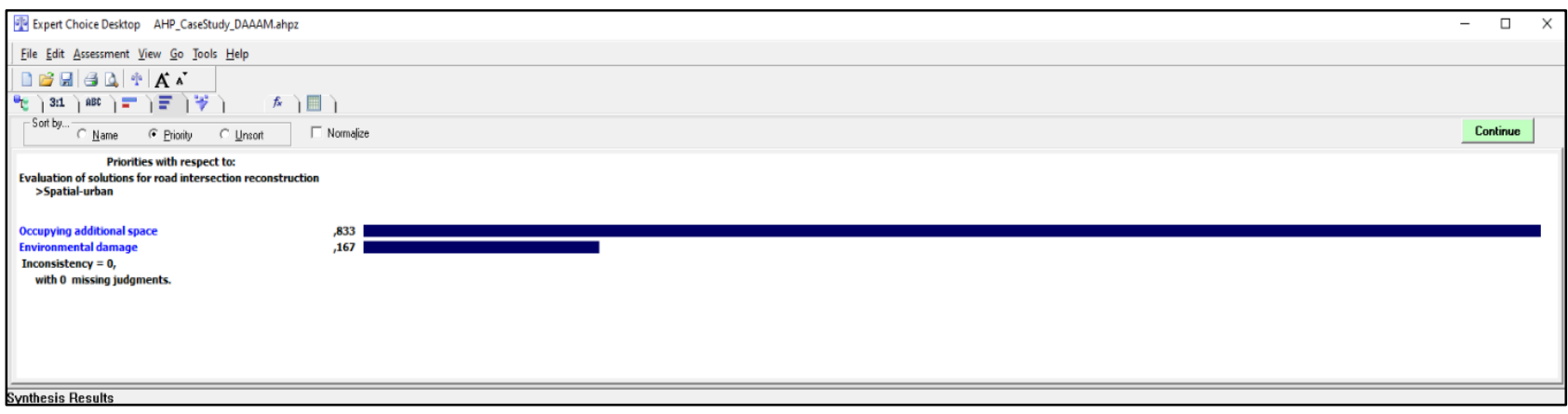

Fig. 9. Ranking of sub-criteria of the criterion "Spatial-urban"

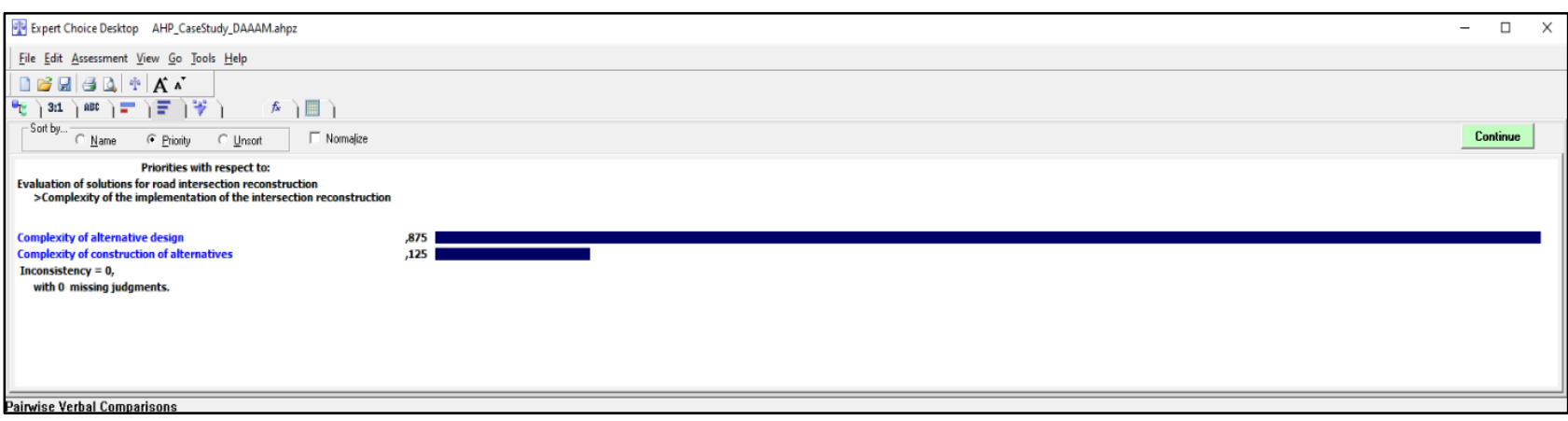

Fig. 10. Ranking of sub-criteria of the criterion "Complexity of the implementation of the intersection reconstruction"

After performing the complete analysis and evaluation of the variants according to criteria and sub-criteria using the AHP method, Alternative $2(28.8 \%)$ has been proposed as the best traffic solution (Fig. 11). It is followed by Alternative $1(25.8 \%)$, Alternative 3 (24.8\%) and Alternative 4 (20.6\%). 


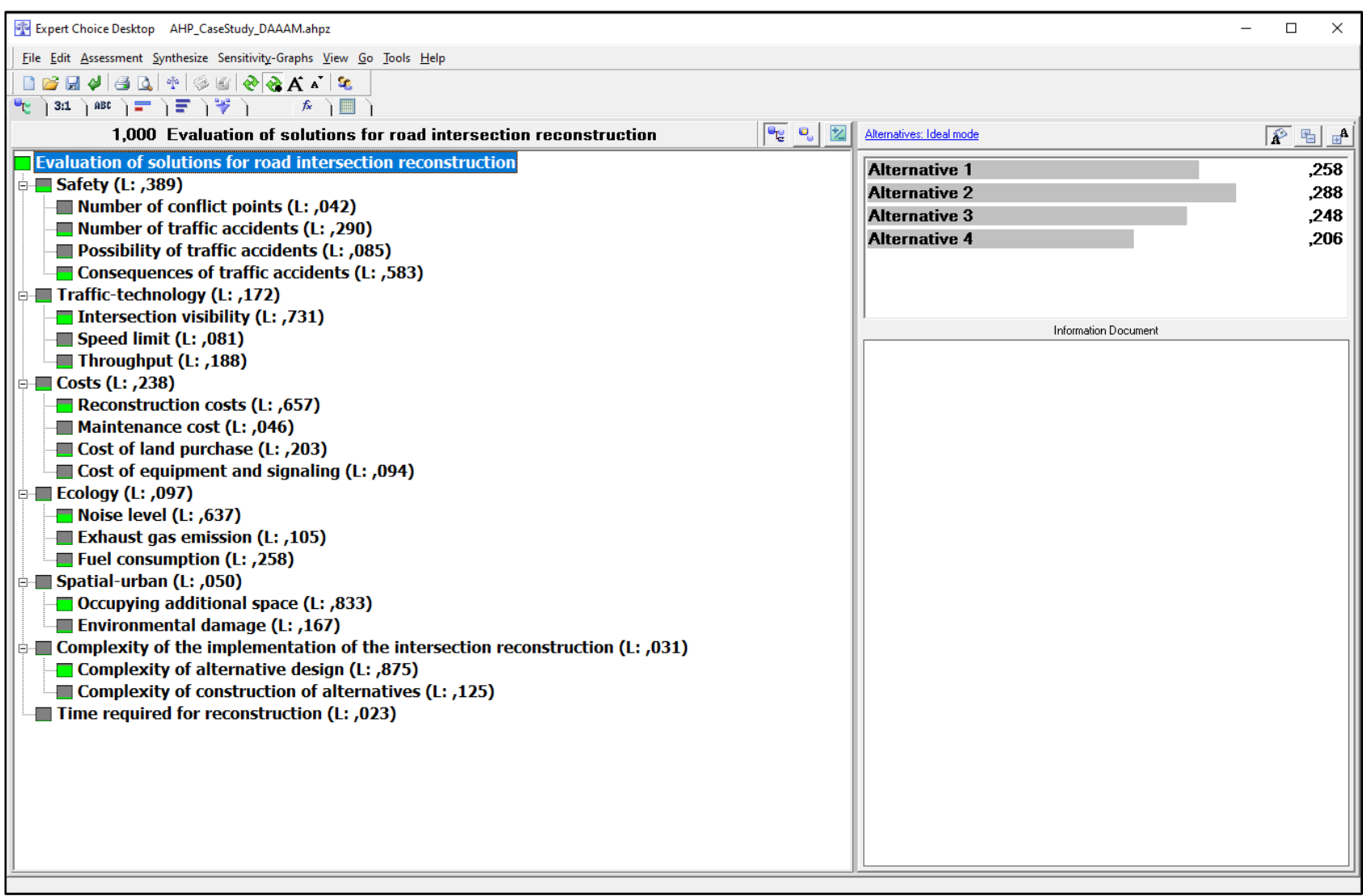

Fig. 11. Overall results - ranking of the criteria, sub-criteria and alternatives in the AHP model (Expert Choice software)

\subsection{Sensitivity analysis}

Sensitivity analysis allows the determination of critical variables or model parameters to assess the project acceptability if the values of the critical project parameters are changed. Critical variables are those variables whose positive or negative variations can have the most significant impact on the financial or economic results.

The criteria for determining the efficiency of investments start from the assumption that all the parameters taken in the budget are realistic, both at the time of the budget and in perspective. However, it is challenging to assess the value of individual baseline parameters for the near future, especially for the distant future, i.e. during the determination of investment efficiency (Baric et al., 2007).

Sensitivity analysis represents the final step of the AHP method. In the AHP method, a change in the input values implies a change in the weights of the criteria or sub-criteria. Based on the sensitivity analysis, the project sensitivity can be investigated if differences in critical decision variables change (Baric et al., 2007). Fig. 12 shows the conclusions reached earlier. The most important criterion is safety, and the optimum variant of the multi-criteria analysis is Alternative 2. 
Baric, D.: Multi-criteria Analysis of Technical Solutions for Road Intersection Reco...

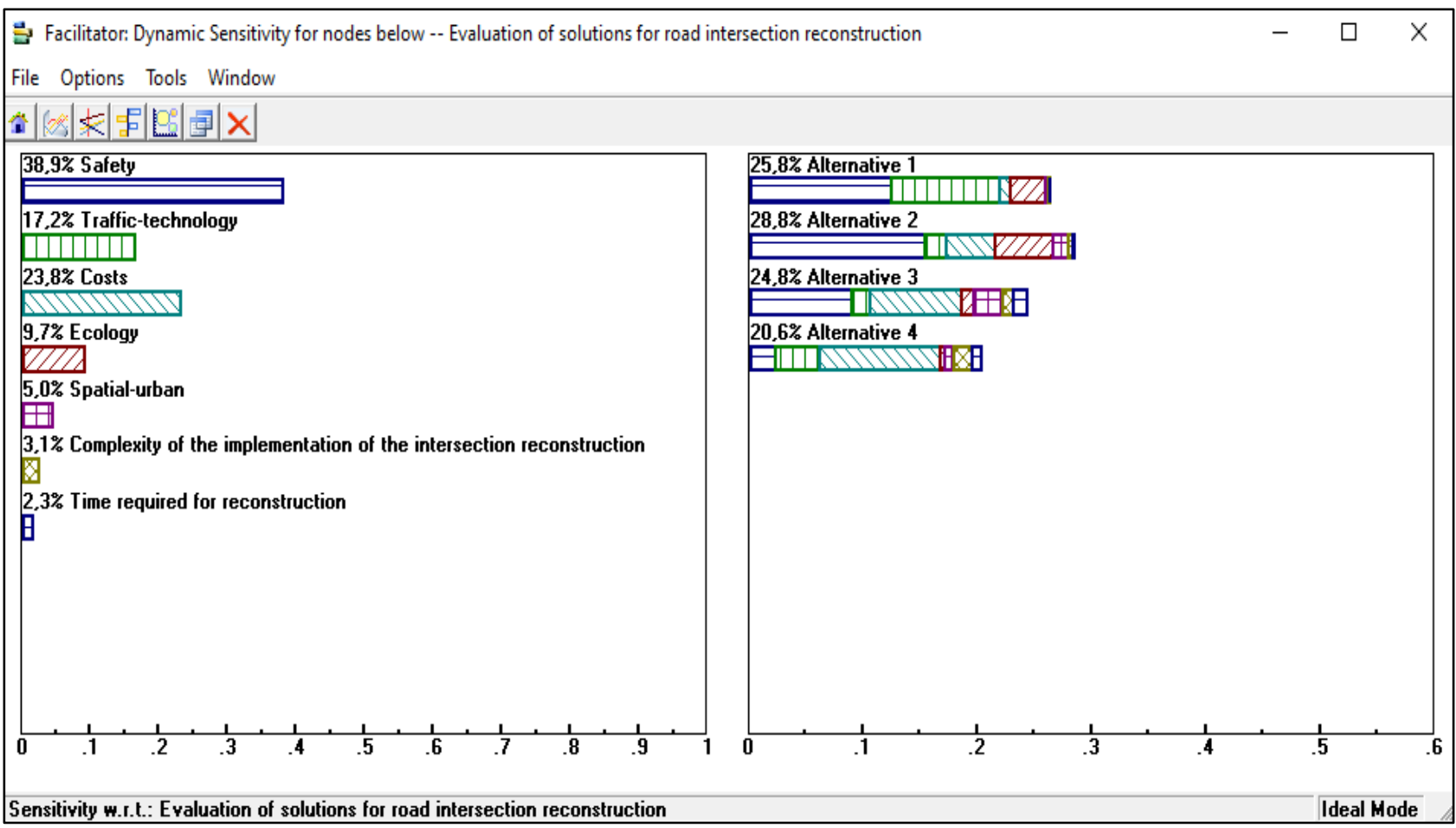

Fig. 1. Sensitivity analysis, dynamic graph - optimal alternative

Whether Alternative 2 would be the optimal solution if the importance of some key criteria were changed was checked in the sensitivity analysis. Since the importance of the cost criterion changes frequently, a simulation was made for the subject model as well. If there is a change in the importance of the criterion cost from $23.8 \%$ to $43 \%$, then the optimal solution becomes Alternative 3 (Fig. 13).

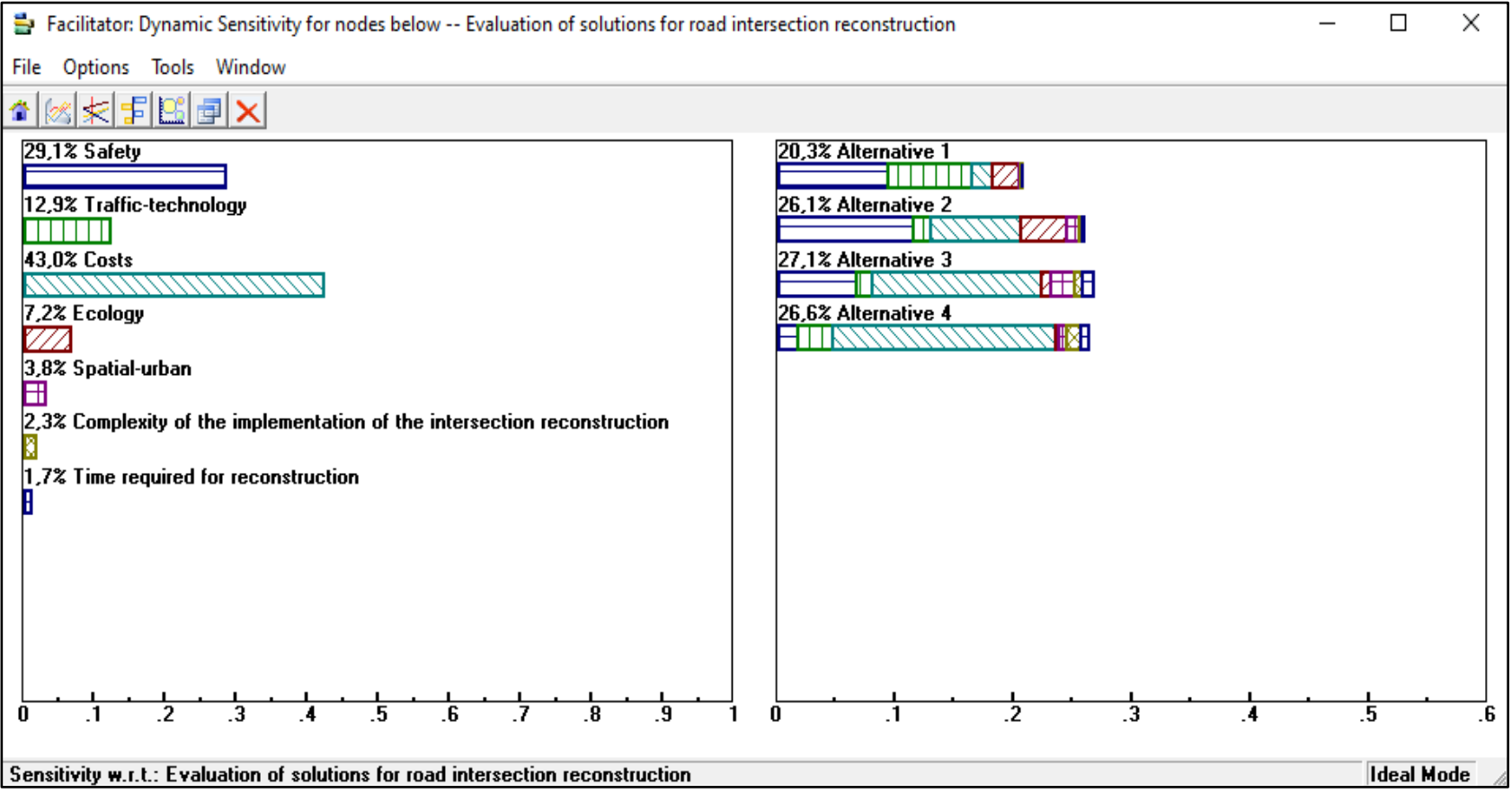

Fig. 2. Dynamic sensitivity - changed state, Alternative 3

Increasing the importance of criterion cost from $23.8 \%$ to $51 \%$, Alternative 4 becomes the optimal solution (Fig. 14). 


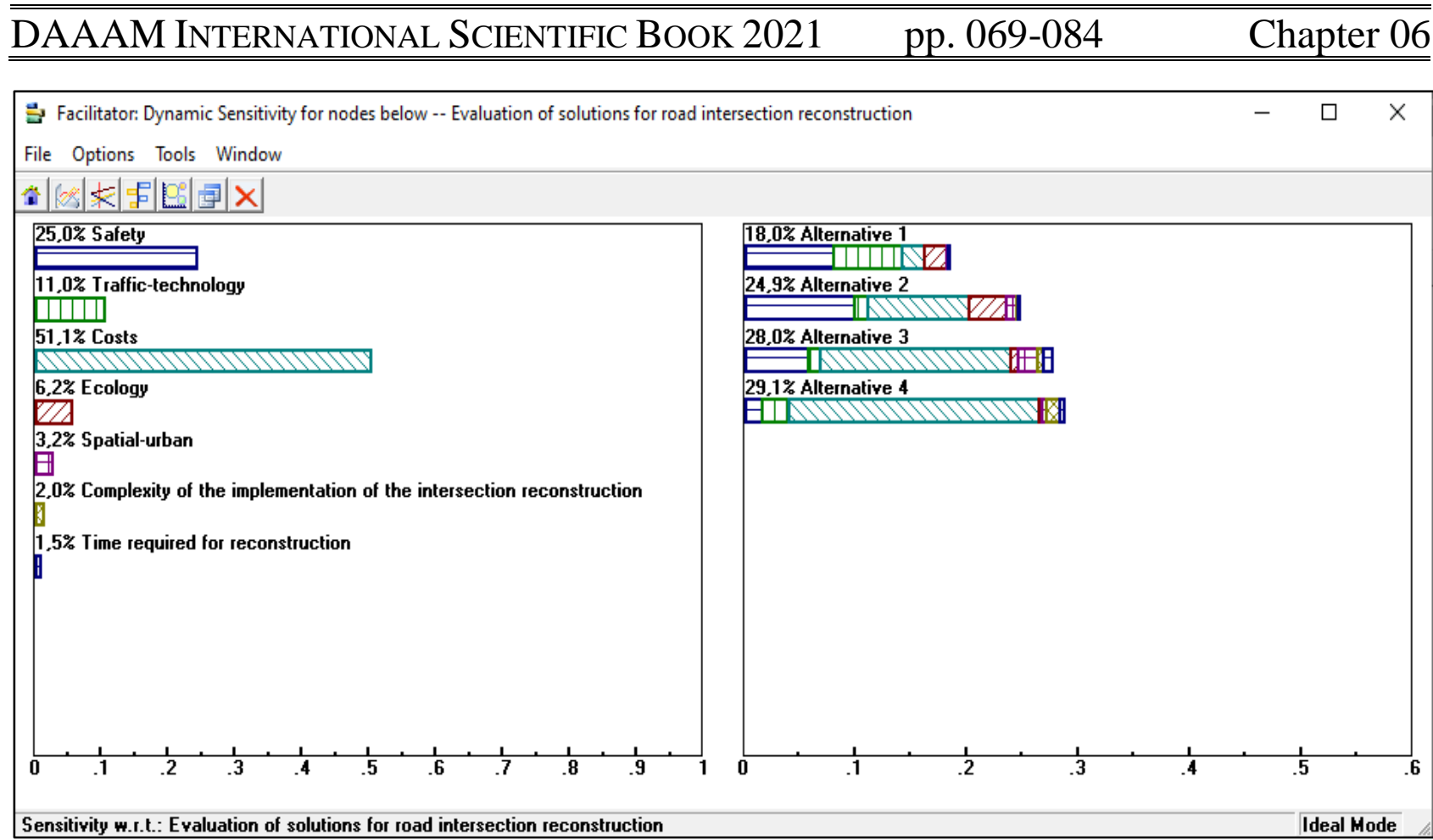

Fig. 3. Dynamic sensitivity - changed state, Alternative 4

\section{Discussion and conclusion}

The main goal of this study was to apply the AHP method (Analytic Hierarchy Process) to evaluate the possible alternatives for the reconstruction of road intersection through various criteria and sub-criteria. The case study presents the intersection of Stubicka Street, Marija Juric Zagorka Street and Zagorsko naselje Street in Oroslavje. The idea was for this intersection to propose new solutions, evaluate them with a relevant, scientifically based method (in this case, the AHP), and choose the optimal variant to make this intersection as safe as possible for all traffic participants. When choosing the optimal variant, it is necessary to perform a detailed analysis of the current condition of the intersection. To obtain information on the traffic load of the intersection in question, it was required to perform a traffic count, which was the basis for the proposal and draft of the proposed variants. After a detailed analysis of the intersection, four alternatives were proposed: Alternative 1 - roundabout; Alternative 2 - intersection with mini-roundabout; Alternative 3 - intersection controlled by traffic lights; Alternative 4 - installation of new and renovation/replacement of the existing horizontal and vertical signalization and increase of the field of view from all entries. The alternatives were evaluated by the AHP method. Using the AHP method means that alternatives were evaluated according to several criteria and their sub-criteria. In this case study, the presented four alternatives were evaluated by seven criteria (safety, traffic-technology, costs, ecology, spatial-urban, complexity of the implementation of the intersection reconstruction, time required for reconstruction) and their 18 subcriteria.

The software tool Expert Choice was used in the application of the AHP method. Based on the applied AHP method by which the alternatives were evaluated, it can be concluded that Alternative 2 (intersection with a mini-roundabout) is the optimal solution. In Alternative 2, the sub-criteria Noise, Emissions and Fuel Consumption are 
the lowest of all the proposed variants, the number of conflict points decreased from 32 to 8 , the consequences of traffic accidents are less due to speed limits of up to 30 $\mathrm{km} / \mathrm{h}$, which directly increases the safety of all participants at the intersection in question. The only disadvantage of Alternative 2 is the higher costs due to purchasing the surrounding land and the more complex reconstruction of the intersection. Alternative 1 is very similar to Alternative 2 . Still, the conducted analyses did not show optimal primary unacceptable values according to sub-criteria and high-ranking criteria (much higher costs of overall reconstruction, land acquisition, maintenance, as well as greater complexity of the design and construction of the proposed alternative).

To check the robustness of the proposed AHP model and the optimal alternative, a sensitivity analysis was performed. Sensitivity analysis showed that the proposed AHP model is sensitive to the weight (importance) of the criterion cost. However, the change in the weight of the criterion cost affects the optimal solution only in a significant increase in its importance (increasing from $23.8 \%$ to $43 \%$ and then to $51 \%$ ) in relation to the model. Therefore, it does not pose a substantial threat to the choice of the optimal solution. The proposed AHP model with its criteria weighting structure may help the policymakers to select the appropriate road intersection design projects for the implementation.

Future work should conduct a survey of road traffic engineering experts from and outside Croatia to validate our results regarding the weighting of criteria and subcriteria. It is possible that such work may affect the recommended road intersection design in the presented case study. Future research should aim to generalize our findings to a broader range of situations as well. For example, expert surveys could compare the importance of other parameters from different areas such as urban planning, land use, economy, ecology, etc.

\section{References}

Abd, K.; Abhary, K. \& Marian, R. (2017). Development of Fuzzy AHP and TOPSIS Approach for Multiobjective Scheduling Problems in Robotic Flexible Assembly Cells, Chapter 20 in DAAAM International Scientific Book 2017, pp.265-278, B. Katalinic (Ed.), Published by DAAAM International, ISBN 978-3-902734-12-9, ISSN 1726-9687, Vienna, Austria, DOI: 10.2507/daaam.scibook.2017.20

Aghdaie, M.H.; Hashemkhani Zolfani, S. \& Zavadskas, E.K. (2012). Prioritizing constructing projects of municipalities based on AHP and COPRAS-G: a case study about footbridges in Iran. The Baltic Journal of Road and Bridge Engineering, Vol. 7, No. 2, pp. 145-153

Babic, F. (2019). Visekriterijska analiza varijanata rekonstrukcije raskrizja Stubicke ulice, Ulice Marije Juric Zagorke i ulice Zagorsko naselje u Oroslavju, University of Zagreb, Faculty of Transport and Traffic Sciences, Zagreb, Master thesis (in Croatian) Bakioglu, G. \& Atahan, A.O. (2021). AHP integrated TOPSIS and VIKOR methods with Pythagorean fuzzy sets to prioritize risks in self-driving vehicles. Appl Soft Comput, Vol. 99, pp. 106-948. https://doi.org/10.1016/J.ASOC.2020.106948 
Baric, D.; Curepic, D. \& Radacic, Z. (2007). Implementation of relevant methods in assessing traffic-technological projects. Promet - Traffic \& Transportation. Vol. 19, No. 5, pp. 329-336, ISSN: 0353-5320

Baric, D. \& Pizeta, F. (2018). An AHP model for level crossing design, International Journal of Safety and Security Engineering, Vol. 8, No. 1, pp. 65-76

Ceric, A.; Marcic, D. \& Kovacevic, M.S. (2013). Applying the analytic network process for risk assessment in sustainable ground improvement. Gradevinar, Vol. 65, No. 10, pp. 919-929

Dzemydiene, D.; Burinskiene, A. \& Miliauskas, A. (2021). Integration of MultiCriteria Decision Support with Infrastructure of Smart Services for Sustainable MultiModal Transportation of Freights. Sustainability, Vol. 21, No. 13, 4675. https://doi.org/10.3390/su13094675

D’orso, G.; Migliore, M.; Peri, G. \& Rizzo, G. (2020). Using AHP methodology for prioritizing the actions in the transport sector in the frame of SECAPs, 2020 IEEE, pp. 1-6, doi: 10.1109/EEEIC/ICPSEurope49358.2020.9160591.

Gholami, M.H. \& Seyyed-Esfahani, M. (2012). An integrated framework for competitive market strategy selection by using Fuzzy AHP. Tehnicki vjesnik Technical Gazette, Vol. 19, No. 4, pp.769-780.

Henke, I.; Carteni, A.; Molitierno, C. \& Errico, A. (2020). Decision-Making in the Transport Sector: A Sustainable Evaluation Method for Road Infrastructure, Sustainability 2020, Vol. 12, No. 3, 764. https://doi.org/10.3390/su12030764

Karleusa, B.; Dragicevic, N. \& Deluka-Tibljas, A. (2013). Review of multicriteriaanalysis methods application in decision making about transport infrastructure, Građevinar, Vol. 65, No. 7, pp. 619-631, https://doi.org/10.14256/JCE.850.2013 Ministry of the Interior (2020), Internal data

Nowak, M. (2005). Investment projects evaluation by simulation and multiple criteria decision aiding procedure. Journal of Civil Engineering and Management, Vol. 11, No. 3, pp.193-202

Podvezko, V. (2009). Application of AHP technique. Journal of Business Economics and Management, Vol. 10, No. 2, pp.181-189

Rouyendegh, B.D. \& Erkan, T.E. (2012). Selection of academic staff using the fuzzy analytic hierarchy process (FAHP): a pilot study. Tehnicki vjesnik - Technical Gazette, Vol. 19, No. 4, pp. 923-929

Saaty T.L. (1984) The Analytic Hierarchy Process: Decision Making in Complex Environments. In: Avenhaus R., Huber R.K. (eds) Quantitative Assessment in Arms Control. Springer, Boston, MA. https://doi.org/10.1007/978-1-4613-2805-6_12

Saaty T.L. (1988) What is the Analytic Hierarchy Process?. In: Mitra G., Greenberg H.J., Lootsma F.A., Rijkaert M.J., Zimmermann H.J. (eds) Mathematical Models for Decision Support. NATO ASI Series (Series F: Computer and Systems Sciences), vol 48. Springer, Berlin, Heidelberg. https://doi.org/10.1007/978-3-642-83555-1_5

Saaty, T.L. (1995). Transport Planning with Multiple Criteria - the Analytic Hierarchy Process Applications and Progress Review. Journal of Advanced Transportation, Vol. 29, No. 1, pp. 81-126 
Stojcic, M.; Zavadskas, E.K.; Pamucar, D.; Stevic, Z. \& Mardani, A. (2019). Application of MCDM Methods in Sustainability Engineering: A Literature Review 2008-2018, Symmetry 2019, Vol. 11, No. 3, 350.

Surdonja, S.; Kisic, I.; Deluka-Tibljas, A. \& Karleusa, B. (2019). Use of AHP method in the traffic planning - Example of selecting an optimal intersection type, AIP Conference Proceedings, E. Simos, T.; Kalogiratou, Z.; Monovasilis, T. (ur.). Online: AIP Publishing, 2019. 160002, 6 doi:10.1063/1.5138070

Tang, J.; Deng, M.; Huang, J. \& Liu, H. (2019). A Novel Method for Road Intersection Construction From Vehicle Trajectory Data, IEEE Access, Vol. 7, pp. 95065-95074, 2019, doi: 10.1109/ACCESS.2019.2929124

Vidal, L.A.; Marle, F. \& Bocquet, J.C. (2011). Using a Delphi process and the Analytic Hierarchy Process (AHP) to evaluate the complexity of projects. Expert Systems with Applications, Vol. 38, No. 5, pp. 5388-5405

Zak, J. \& Kruszyriski, M. (2015). Application of AHP and ELECTRE III/IV Methods to Multiple Level, Multiple Criteria Evaluation of Urban Transportation Projects, Transportation Research Procedia, Vol.10, pp. 820-830

***https://sestar.irb.hr/instrumenti_show.php?ID=3010\&page - Sestar - database of scientific research instruments, A COUNTcam camera, Accessed on: 2021-09-15 ***https://sestar.irb.hr/instrumenti_show.php?ID=3011\&page=0 - Sestar - database of scientific research instruments, software tool COUNTpro and COUNTpad 2, Accessed on: 2021-09-15 